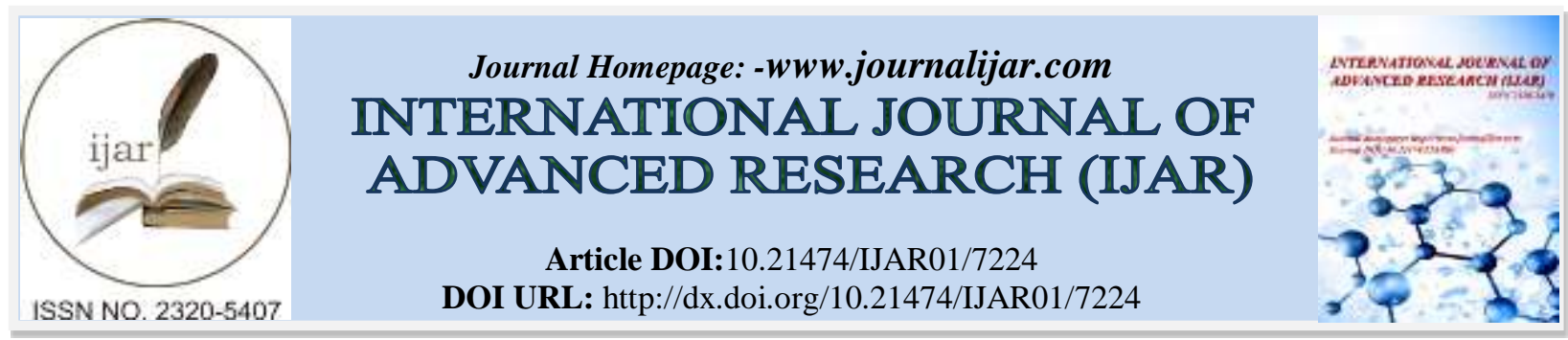

RESEARCH ARTICLE

\title{
EFFECT OF RELIANCE JIO ON DIGITAL INDIA.
}

Tanya Daga, Vipul Chandra and Anas Malik.

1. MBA Scholar, MBA Scholar, MBA Scholar

2. MBA (Oil and Gas) School Of Business

3. University of Petroleum and Energy Studies, Dehradun, India - 248001

\section{Manuscript Info}

Manuscript History

Received: 07 April 2018

Final Accepted: 09 May 2018

Published: June 2018

Keywords:-

Telecommunication Industry, Customer

Satisfaction, Customer Preferences,

Digital India and Reliance Jio.

\begin{abstract}
The IT ministry defines Digital India's vision as follows: "Digital infrastructure as a utility to every citizen, governance and services on demand, and empowerment of citizen." Digital India is to empower common people using broadband by providing E-governance, education and health services to them even in isolated areas.

The purpose of the study is to analyse the impact of Reliance JIO on digital India and how it revolutionized the Indian telecommunication market. The Supporting data were collected from various demographic regions of India by questionnaire survey and group interviews; for getting customer feedback on the loyalty and impact on competitive brands. Few demographic reasons are also linked with the user service preference. The Study also analyses the role of government combined with Reliance JIO, towards the digitization of India.
\end{abstract}

Copy Right, IJAR, 2018,. All rights reserved.

\section{Introduction:-}

Telecommunication industry is one of the most developing ventures which evolved quickly in last decade. The mobile economy in India is increasing very fast and will add significantly to India's GDP. India has the world's second biggest phone clients ( both fixed and mobile phone) with 1.053 billion subscribers by 31/08/2016[1] and second-largest Internet user-base and to keep up high development rate throughout the following couple of years as individuals change to smart phones and gradually move up to $4 \mathrm{G}$. By providing different plans like free web, free calling, and $4 \mathrm{~g}$ network give a serious threat to others. Jio rises a new choice and other service provider confront another sort of challenge and find difficult to cope up with new conditions. Relatively after around one and a half decades, Jio backed by Mukesh Ambani, got tremor the whole Indian telecom industry. Reliance JIO is being broadcasted as one of the world's biggest start-up, with an initial investment of around Rs.1.5 Lakh crore, and it is one of the greatest green-field digital enterprises. This journey is almost six years in creation, with Reliance Industries Limited buying 96\% stake in Infotel Broadband Services Limited (IBSL) for approx. Rs. 4,800crores in June 2010, which had gained the BWA spectrum in all 22 telecom circles during the spectrum auctions which took place earlier in that year[2]. JIO now owns spectrum in an 1800-MHz band in 18 circles, and also owns pan-India $850-\mathrm{MHz}$ and 2,300-MHz spectrum. This way JIO has strengthened its passive infrastructure which is the key and the reason that it can compete with well-established telecom players and offer high-speed of data and voice calls. It has its headquarters in Navi Mumbai, India. They offered mobile telephony and wireless broadband products. On 5th September 2016, they commercially launched their services. Within the first month, JIO announced that it had 
acquired 16 million subscribers of their commercial operations. This is the fastest increase by any mobile network operator anywhere in the world. JIO crossed 10 crore endorsers on 22nd February 2017.

The entry of Reliance JIO has forced giants like Airtel, Vodafone, Idea service providers to cut off their plans. Reliance JIO announced that until the end of February 2016, 7 customers per second of every day subscribing to JIO. The market leader Airtel has 26 crores 4 lakhs subscribers which were founded in the year 1995. This study is about to identify the factors which facilitate the rapid growth of Reliance JIO telecommunication industry. To identify the effect of "Reliance Jio" on "digitization of India".

\section{Literature Review:-}

Rajbinder Singh [Impact of Reliance Jio on Indian Telecom Industry: An Empirical Study]:-

Reliance Jio Infocomm Limited announced the launch of its digital services with JIO in Mumbai on ${ }^{\text {st }}$ September 2016 with Jio Welcome Offer; with the vision of best broadband network, maximum market share and superior digital service experiences with affordable and simple tariffs. [3]

\section{[Zakaria's interview with Mukesh Ambani]:-}

During the interview Ambani explains to Zakaria why he is taking high risks with his transformational Reliance Jio to bring high quality digital broadband connectivity to a global cohort the Economist calls the "brainiest, besteducated generation ever"

I believe that humanity is at the doorstep of massive change and we are just at the beginning of the information and digital age. And, in the next 20 years, in a networked society, we are going to have change much more than we have seen in the last 100 years. It's really digitisation and the digital world that is going to lead this. [4]

Surabhi Singh [Consumer Attitude towards Reliance Jio in India]-studied the perception of customers about Jio network, the consumer attitude towards other networks with Jio and to analyze the customer's satisfaction towards Jio network. The study mentioned that the use of Jio for Internet usage is high. Jio has given maximum utility to their customers in the form of high- speed Wi-Fi, economy, responsiveness, and technology. [5]

R. Sorna Priya and M. Sathiya [Customer Satisfaction towards Reliance Jio Network] studied the attentiveness of customers about Jio network, the preference of customers towards other networks with Jio and it also analyze the customer's satisfaction towards Jio network. The study mentioned that Reliance Jio has to improve their network coverage and to distribute out the calling congestion, and also the company can achieve the 100 percentage satisfaction of their customer. [6]

\section{Objectives Of The Study:-}

1. To study the impact of JIO on Digital India.

2. To analyse the internet Service preference.

3. To study the preference of customer towards JIO among different demographic region.

\section{Methodology:-}

1. This research is the combination of "applied" and the "qualitative" type of research.

2. The sampling technique used is "simple random sampling" from the population, which is taken across the nation.

3. This research has the primary data collection methodology and it has been collected from the structured questionnaire.

4. The analysis of the content involved the statistical tools i.e. the bi-variet comparison, chart preparation, "McNemar hypothesis" and the Microsoft excel tool is being used.

\section{NOTE:-}

The population which we have taken is familiar with the term "Digitization" and most of them are undergraduate and the postgraduate students. The demography of the nation is divided in six parts,

1. Northern- U.P, Uttarakhand, Delhi, Punjab, Hariyana, Himanchal, J\&K, the seven sisters states of India.

2. Western- Maharashtra, Gujarat, Goa, Rajasthan.

3. Eastern- Bihar, West Bengal, Jharkhand, Orissa.

4. Central- M.P, Chhattisgarh. 


\section{Data Interpretation:-}

India will have world's largest youth population by 2020 according to Financial Xpress. And youth always drive the country

For a step towards the digitisation JIO is a major contributor and $77 \%$ of the population of upper triangle of the country use JIO services and among them $83 \%$ belongs to youth (20-40 age groups).

There are no two ways about it that the data consumption has increased drastically after JIO and the people ae more aware about their services and the youth are now using for various reasons like Entertainment,Education, Shopping, Payment and booking, etc.

The average age of employment in the India is 29 . Our data research shows that majority of respondents belongs to 20-40 age group. This age group is more aware about the socioeconomic change and edutainment (combines aspects of education and entertainment).

It is evident from the major group of 20-40 that, in addition to the many impacts of digital technology, that online news channel, YouTube, GoogleLib, Kindle, Paytm, Goibibo, redbus, MMT, Flipkart, Amazon, Myntra, etc, they have a considerable and wide positive impact on digital India.

According to the survey, it is appreciable that interactive technologies are currently promote digitisation, with sectional result of entertainment (30\%), Education (25\%), Payment and Booking (19\%) and rest for shopping and other purpose.

\section{Purchasing power:-}

Consumers and especially Generation C (the age of youngsters who, by 2020, will have dependably lived in a basically advanced world) are as of now completely adjusted to the computerized condition. They normally hope to dependably be associated, will share individual information, and trust referrals from their dearest companions more than from understood brands.

\section{Technological Advancement:-}

The increasing affordability of broadband is expanding the reach of technology to billions of consumers. In parallel, minimal effort brilliant gadgets are being sent in each industry. Distributed computing and the unlimited data organising hardware it requires, is growing quickly.

\section{Financial Aspect:-}

The financial advantages to be caught through digitization are quantifiable. A surge of capital has filled the new digitization advances and organizations, and the general population markets compensate early movers with phenomenal valuations.

Data Consumption:Survey Data for "Data Consumption"

\begin{tabular}{|c|c|c|}
\hline & Before JIO & After JIO \\
\hline 0-10GB & 152 & 60 \\
\hline 10+GB & 24 & 116 \\
\hline
\end{tabular}

From our nationwide survey, the result shows that $86.3 \%$ people were consumed the mobile data up to 10 GB only, before Jio came into the Indian market whereas the contribution of people with more than 10+ GB data consumption is only $13.7 \%$. After Jio entrance, the mobile data consumption of more than $10 \mathrm{~GB}$, increased drastically by $383 \%$ with market share increased from $13.7 \%$ to $65.9 \%$ and it clearly shows the effect of Jio towards the usage of the internet services.

The validation of this fact is analysed by McNemar Test.

The test and result is as follow. 


\section{Contingency Table:-}

\begin{tabular}{|c|c|c|c|}
\hline & After Jio 0-10 & After Jio 10+ & Total \\
\hline Before Jio 0-10 & 55 & 97 & 152 \\
\hline Before Jio 10+ & 5 & 19 & 24 \\
\hline Total & 60 & 116 & 176 \\
\hline
\end{tabular}

Mc Nemar test (Asymptotic p-value) / Two-tailed test:-

\begin{tabular}{|c|c|}
\hline $\mathbf{Q}$ & 101.895 \\
\hline$|\mathbf{z}|$ (Observed value) & 10.094 \\
\hline$|\mathbf{z}|$ (Critical value) & 1.960 \\
\hline $\mathbf{p}$-value (Two-tailed) & $<0.0001$ \\
\hline alpha & 0.05 \\
\hline
\end{tabular}

Mc Nemar test (Exact p-value) / Two-tailed test:-

\begin{tabular}{|c|r|}
\hline $\mathbf{Q}$ & 103.444 \\
\hline$|\mathbf{z}|$ (Observed value) & 10.171 \\
\hline$|\mathbf{z}|$ (Critical value) & 1.912 \\
\hline p-value (Two-tailed) & $<0.0001$ \\
\hline alpha & 0.05 \\
\hline
\end{tabular}

\section{Test Interpretation:-}

Ho: The amount of data used before and after Jio is same.

Ha: The amount of data used before and after Jio is different.

As the computed p-value is lower than the significance level alpha $=0.05$, one should reject the null hypothesis Ho, and accept the alternative hypothesis Ha.

The risk to reject the null hypothesis Ho while it is true is lower than $0.01 \%$.

The result shows that we have to accept the alternative hypothesis i.e. "The amount of data used before and after Jio is different".

So this test validates our survey.

\section{Finding And Conclusion:-}

This study reveals that majority of our respondents belongs to 20-40 age groups and majority of them are in the favour of JIO service and they believe that JIO is a major contribution in digitization; their data consumption is increased drastically. JIO came with revolutionizing market strategy of cheapest data cost of the world and according to our survey the Jio users are more than $60 \%$ and they are still growing positively and it not only promote digitization but it also connect the people and giving them to enhance their lifestyle.

At the same time the Indian Government and Honourable Prime Minister Mr. Narendra Modi is trying hard to go more towards the digitization and he has also launched the scheme of "Digital India"; and our survey shows that more than $80 \%$ people believe that Jio is one of the reasons for digital change in India. Our result supports the digital India mission of Indian government.

\section{Future Scope:-}

The digital India mission states "Digital Infrastructure as a Utility of every citizen" and the "availability of services in the real time from online and mobile platforms" for every Indian [7]. In this mission, the cheap mobile data availability is big concern and it has been sorted out by the Reliance Jio and the effect is being shown by our research.

But the players like Paytm, Amazon, Myntra, etc also play the important role in the digitization and it will be interesting to see how these players combined with Jio have an impact on the "changing telecommunication market" and "the digital India campaign". 


\section{Charts:-}
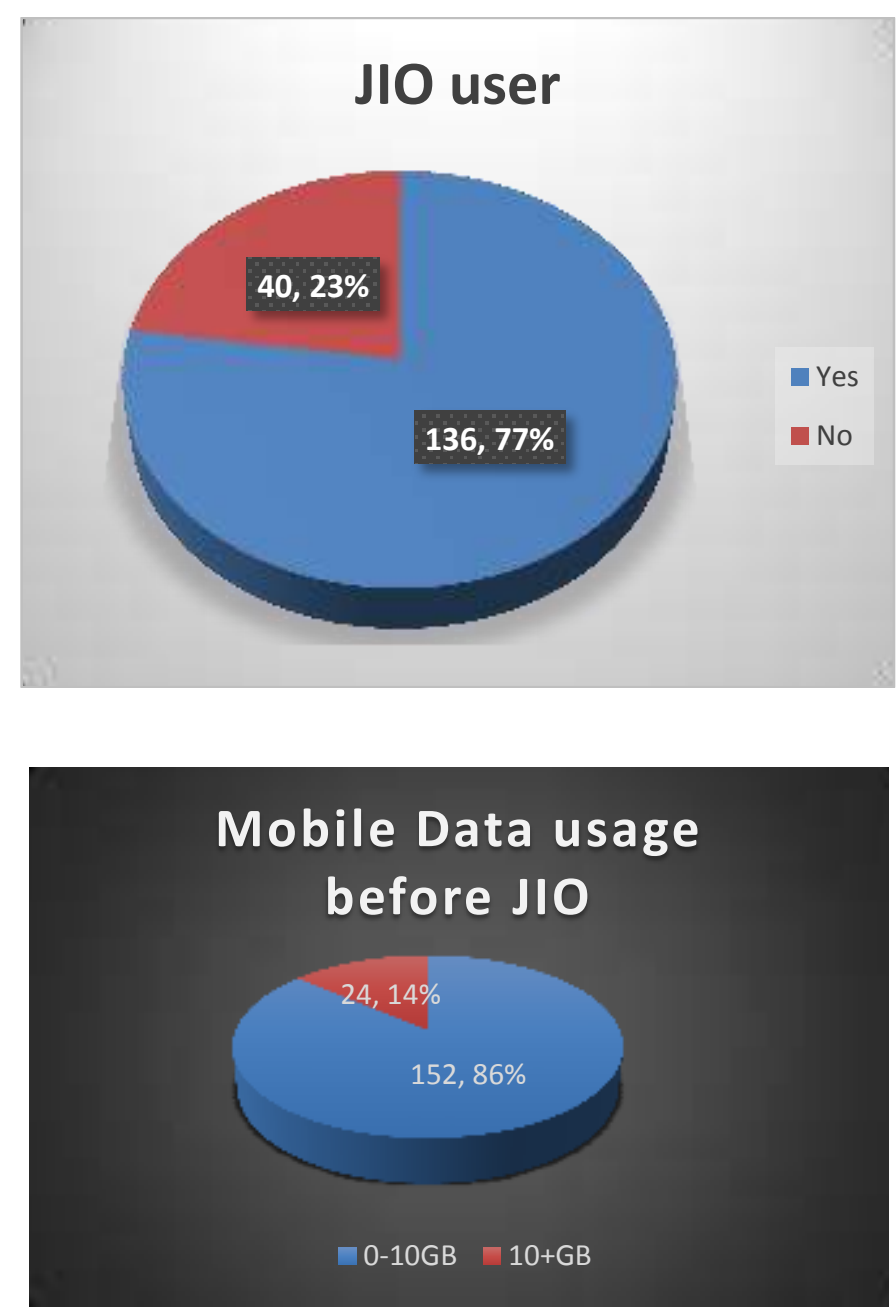

\section{Mobile Data usage after JIO}



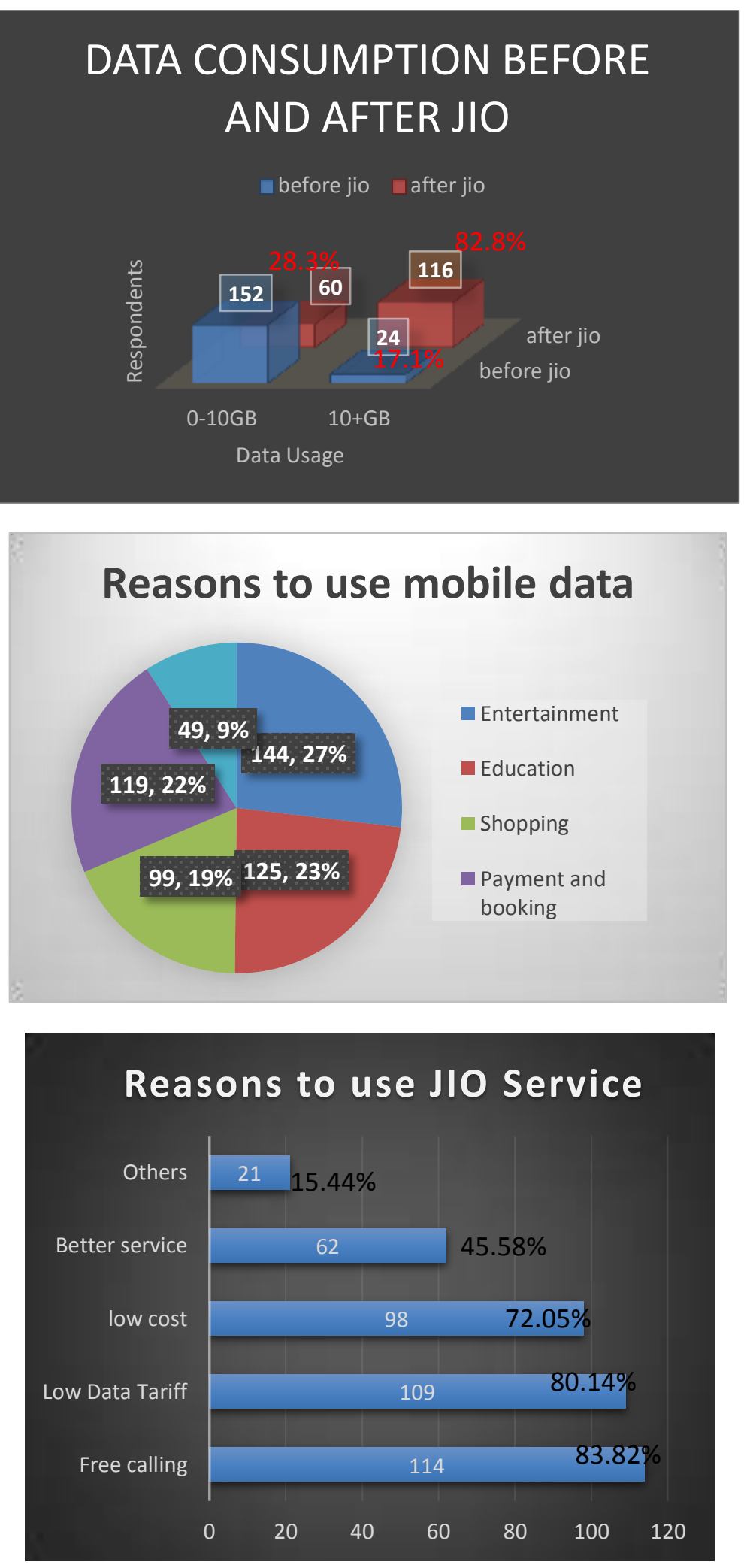

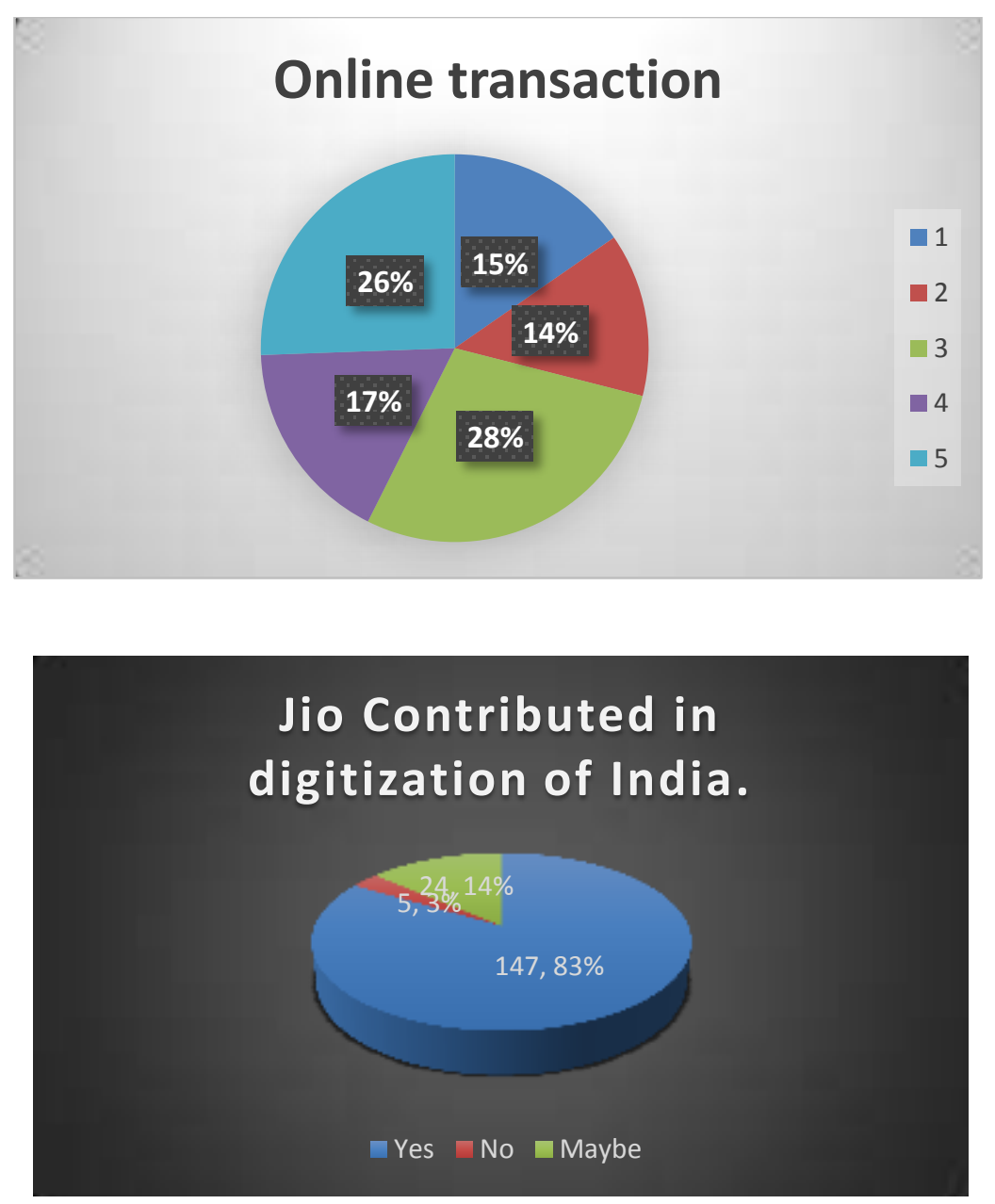

\section{Reference:-}

1. Equipment, T., \& Council, E. P. (2018). Sector in India, 4-7. https://www.telecomepc.in/about-us/telecomsector-in-india/

2. Haq, N. (2017). Impact of Reliance JIO on the Indian Telecom Industry, (3), 259-263.

3. Singh, R. (2017). Impact of Reliance JIO on Indian Telecom Industry: An Empirical Study, 5(07), 6469-6474. https://doi.org/10.18535/ijsrm/v5i7.83

4. Ambani, M. (2018). Full text of the Mukesh Ambani interview on Fareed Zakaria GPS, 2016-2019.

5. Singh, S. (2017). Consumer Attitude towards Reliance Jio in India, 777.

6. Sorna, R., \& Sathiya, M. (2017). Customer Satisfaction towards Reliance Jio Network, 6(1), 21-27.

7. http://www.digitalindia.gov.in/content/about-programme. 